forest areas sufficiently indicate how strict for a long period of time this careful protection has proved; nor should it be beyond the powers of the Indian sylviculturist to extend the areas still occupied by this old indigenous evergreen forest.

Bor's investigations, as he says, are by no means complete; they "represent the gatherings of one rainy season in Shillong on the few occasions when holidays or Sundays afforded a release from the pressure of other work. Great as is the similarity of the floristic of the three areas based on these collections, it is believed that further work will make the similarity even closer". The tallest trees, says the author, in these dark and gloomy evergreen woods, are perhaps $60 \mathrm{ft}$. tall. The dominant stems have smooth, cylindrical boles and thick crowns which touch. The trunks and branches of the trees on the margins are loaded with lichens, mosses, orchids and other epiphytes. A small-tree layer can at times be distinguished, but it is not at all distinct. The shrubby and herbaceous layers are in places well marked and in others almost non-existent. The soil is covered with mosses and Selaginellas and is deeply stained with humus. Whenever a gap occurs in the canopy owing to the disappearance of a giant, natural regeneration of the dominant species is satisfactory. In his list of species, Bor enumerates 32 canopy trees, 66 small trees, 80 shrubs, 120 herbs, 30 ferns, 20 grasses and sedges, 8 parasites and 44 climbers, which endorses Hooker's remark on the richness of the flora of the region.

The author writes: "It is realized that a far larger number of the groves would have to be examined before reliable details of fidelity and constancy for the species could be obtained, but the object of this paper is not a statistical examination of the groves but an inquiry into the ecological status of the groves based upon the available data".

\section{MANUFACTURE OF OPTICAL GLASS}

$\mathrm{T}$ HE production of optical glass is one of the most difficult as well as one of the most interesting of manufacturing processes. Fraunhofer was the first to realize the necessity for improvement in the manufacture of glass in order to bring it to the necessary degree of homogeneity and to make it free from internal strain, essential requirements for optical glass. It may be said that it has taken more than a hundred and fifty years to bring the art of optical glass manufacture to its present state. Messrs. Chance Bros. have been engaged on the task for nearly a hundred and twenty years and the Chance-Parsons optical glass embodies their experience, together with the newer research work in their laboratories as well as that of the firm owned by the late Sir Charles Parsons, under whom notable advances were made.

It is a cause for satisfaction to record the high quality of the glass produced by a British firm, even under war conditions. In homogeneity and freedom from strain and mechanical defects, Chance-Parsons optical glass can compare favourably with that of any other maker. The publication by Messrs. ChanceParsons of a new catalogue of optical glass is thus something of an event for the optical designer and manufacturer, as well as for the physicist, as here is found exact data about glass for condensers, ophthalmic lenses, optical instruments and colour filters.

To measure the advance in the last thirty years it may be recalled that on the outbreak of the War of 1914-18 the British maker listed some dozen types of glass with refractive indexes given for four lines of the spectrum from $C$ to $G^{\prime}$. Now there are nearly one hundred types, and the data cover nine lines fairly evenly spaced over the visual spectrum from helium $b$ to mercury $h$. Refractometry in the infrared and the ultra-violet is still in the laboratory stage. When it is recalled that the same state of affairs existed with respect to the measurements in the visual spectrum until Abbe introduced exact measurements and published the data in a manufacturer's catalogue, it is possible to hope that an extension of the data to include the infra-red and ultra-violet will be a possibility before long. This would be a really useful advance as these regions are becoming of increasing importance in industry as well as in pure science. At present, when information is wanted as to the refractive indexes of any glass in the invisible regions, resort must be had to the inaccurate methods of extrapolation, or to the laboratory.

An innovation in the present catalogue is the introduction of a new system of classifying glasses in order of their stability, based on a thermodyne test devised by Chance Bros. which is said to conform well to the results of atmospheric action. Stability is assessed in terms of the period of time during which the glass may reasonably be expected to show no signs of surface tarnish. It is to be hoped that this classification will in time be extended to all the glasses on the list.

A useful feature of the catalogue is the distinguishing, by heavy type, of those glasses which are made regularly and so can be supplied with a minimum of delay. Furthermore, particular care is paid to the maintenance of a stock of certain glasses which are in very general demand, and these are indicated by an asterisk. These can be repeated, in successive melts, within very close limits of optical properties. The designer and manufacturer are therefore advised to use these wherever possible as a change to a new melt can be looked forward to without misgiving, calling for minimum alteration of the data of the system.

There are no fresh glasses recorded in the present catalogue nor any having the extreme properties claimed recently in patent literature, yet the range is wide and covers the normal requirements of the optician; British optical instrument manufacturers have no cause to complain of the lack of variety of material offered them.

Considerable advance is to be noted in the section relating to colour filters, which should be of particular value in laboratory work and in colorimetry, which is becoming of increasing industrial importance.

Glass filters naturally have not so wide a range as those made from coloured gelatin but have certain advantages. They are usually more stable; are more robust and can be more easily handled in the unprepared state; are cheaper when required to be of optical quality since the working of only one parallel flat is involved instead of two; for the same reason they can be made thinner and lighter; and they have a certain adaptability as the transmission can be varied by suitable choice of thickness.

The filters now offered provide a range of colours from infra-red to ultra-violet, as well as neutral and heat absorbing glass. There is also one (didymium) showing sharp absorption in a narrow region in the neighbourhood of the $D$ line. 
Transmission curves are given for each glass on a separate chart. This supersedes the previous method of plotting densities and is in conformity with other makers' lists. The integrated visible transmission, for a standard lamp and thickness of filter, is also supplied, and a formula given by which the transmission can be calculated for any other thickness. It is believed that there are only two other makers of coloured glass of optical quality in the world, and the English list compares favourably in range with any other.

The makers are to be congratulated on the publication of the new catalogue under present conditions.

H. W. LEE.

\section{MOTION AND FORMATION OF THE PLANETS}

$\mathrm{T}$ WO papers under the title "Gravitational Theory of Planetary Rotation", and "A New Theory of Planetary Formation", by J. Miller, have just appeared (J. Brit. Astro. Assoc., 52, 5 and 6, June and July 1942). Miller shows that a spherical body or a loose agglomeration of particles, held together by gravitational force or cohesion, which is describing an orbit around a central body, will acquire a rotation in a sense opposite to that of revolution. This rotation is produced by the unequal attractions of the central body or centre of force on the near and remote sides of the smaller body, and the axis of rotation will be perpendicular to the orbital plane. The linear velocity of rotation will vary as the diameter of the body, and will also be a function of the distance between the body and the central force. Owing to the fact that a second order term appears in certain computations, the linear velocity will not be exactly proportional to the diameter, and in addition, internal friction between the different strata has an important effect.

A relation between increments of time in rotation rates and increments in diameters is deduced by Miller, and the theoretical times of rotation for the different planets are computed. Some of these agree well with the actual times of rotation, and, where discrepancies occur, it is suggested that the internal frictions of the planets, for which it is difficult to calculate exact figures, are responsible. It is assumed that the solar system once revolved around the centre of a star cluster, which, in turn, was revolving around the centre of the galaxy, and planetary rotations originated as a result of the difference in the attractions on the near and remote sides of the planets, to which reference has already been made. These rotations have been maintained since they were established, though, as pointed out, there were probably other disturbing factors which modified the original rates to a small extent.

No explanation is given in the first paper of planetary formation, but this problem is attacked in the second paper. The sun alone in the solar system is first dealt with, and it is conceived as originally describing an orbit around a centre of force which may be, as in the previous case, a stellar cluster or the galaxy. Under favourable conditions, such as approach to the periphery of the cluster, the disruptive force of the latter, due to its differential attraction, will at a certain stage overcome the combined forces of the sun's gravitational pull on its external layers and of the cohesion of the particles. A portion of the sun will be removed, and as it makes closer approaches to the cluster, more material will be torn off. Miller suggests that the outer planets were removed first, and as the disrupted sun moved closer to the cluster, it lost more and more material which formed the remaining planets, Pluto being the first to be removed at a great distance and Mercury the last when the sun was nearest to the centre of attraction.

The theory differs from the planetesimal hypothesis of Chamberlin and Moulton in many ways. A cluster, not another star, is held to be responsible for the disruption. In addition, internal forces in the sun, caused by the high temperature, are not considered necessary to assist with the ejection of matter. A tentative explanation of Bode's Law is given, but this is not worked out in detail. The physical condition of the sun at the time of the formation of the planets is left an open question; it may have been in a state somewhat resembling its present condition, or it may have been in a seminebulous state. It is assumed that the matter composing the superficial layers did not all possess the same cohesive force, from which it may be inferred that the sun was not entirely nebulous at the time of the disruption, though it may have been very much more extended than it is at present. Miller's theory requires that the outer planets, which were first disrupted, should possess less cohesion than those closer to the sun, so that the cohesive power should increase from Mercury outwards. As, however, great changes have taken place in the planets since their formation. this rule cannot be applied very strictly.

\section{INDIAN FORESTRY RESEARCH*}

$\Delta \mathrm{S}$ a record of useful economic activities, a report A entitled "Forest Research in India and Burma, $1940-41$ " is an encouraging summary of many-sided investigations under difficult conditions. It deals with the work of the Forest Research Institute at Dehra Dun during the period under review. Naturally the outstanding feature of the year's activities has been the influence of the War. At first the demands made upon the staff of the Institute were connected with supplies, but as its work is primarily research it was for this reason capable of dealing only with comparatively small quantities of materials. It became, therefore, wisely agreed that the Institute could not make its best war contribution by turning itself into a supply unit. It has confined its programme in consequence to research work in connexion with various war problems.

While the activities of the Utilisation Branch of the Research Institute were largely engaged upon war work, rather than normal programmes, those of the Botanical and Sylvicultural Branches were more especially engaged on the normal research and other duties where interruption would lead to waste of previous efforts. In the Utilisation Branch many inquiries were dealt with in connexion with timbers for various war uses. These included bamboos for aircraft work and tent poles; timbers for rifle parts and tool handles; containers for ammunition, for packing army boots, etc. As an example it may be

* Forest Research in India and Burma, 1940-41. Part 1: The Forest Research Institute. Pp. 161. (Manager of Publications, Delhi, 1941.) Rs. 1.12 or 28 . $6 d$. 